\title{
Breve discusión conceptual del movimiento estudiantil chileno posterior al 2011: una visión desde las y los estudiantes revolucionarios
}

\section{Brief conceptual discussion of the Chilean student movement after 2011: a vision from the revolutionary students}

\author{
Camila Ignacia Araya Guzmán'1 \\ carayaguzman@gmail.com
}

\begin{abstract}
Resumen
El presente artículo, dará a conocer algunos resultados obtenidos en la investigación "Ideas Políticas y Clivajes en el Movimiento Estudiantil Chileno", los cuales refieren a la dimensión emergente-desde los discursos de jóvenes militantes de organizaciones que se autodefinen marxistas- al cómo se dota de contenido y significancia el movimiento estudiantil, permitiendo construir una pequeña y superficial conceptualización de lo que es -o ha sidoel movimiento estudiantil chileno en el período 2011-2016.

El enfoque metodológico utilizado fue de carácter cualitativo, y se realizaron doce entrevistas ${ }^{2}$ en profundidad a jóvenes hombres y mujeres ${ }^{3}$ militantes de organizaciones políticas-estudiantiles que se autodefinen marxistas y de izquierda revolucionaria, a las cuales se les aplicó un análisis de contenido.
\end{abstract}

\section{Palabras claves}

movimiento estudiantil; significaciones; organizaciones estudiantiles; jóvenes militantes, izquierda revolucionaria.

\begin{abstract}
This article will present some results obtained in the research "Political Ideas and Cleavages in the Chilean Student Movement", which refer to the emerging dimension -from the speeches of young militants of self-defining Marxist organizations- to how it is endowed of content and significance the student movement, allowing to build a small and superficial
\end{abstract}

\footnotetext{
1 Asistente de Investigación Proyecto Fondecyt Postdoctorado № 3170504, titulado "Culturas políticas contestatarias en la movilización universitaria (2012-2017). Narrativas de un proceso en curso". (2017-2020). Centro de Estudios Regionales (CEDER), Universidad de Los Lagos"

${ }^{2}$ Las entrevistas las realizó la investigadora quien escribe, entre los meses de mayo y octubre del año 2016, y están sujetas bajo anonimato según los consentimientos informados.

3 Las y los jóvenes entrevistados se encuentran en la mayoría de edad, además de ser estudiantes universitarios.

Esta obra está sujeta a la Licencia Reconocimiento-NoComercial-CompartirIgual 4.0 Internacional de Creative Commons. http://creativecommons.org/licenses/by-nc-sa/4.0/ 


\section{Breve discusión conceptual del movimiento estudiantil chileno posterior al 2011: una visión desde las y los estudiantes revolucionarios}

conceptualization of what is-or has been-the Chilean student movement in the period 20112016.

The methodological approach used was of a qualitative character, and twelve in-depth interviews were conducted with young men and women militants of political-student organizations that define themselves as Marxists and revolutionary leftists, to whom a content analysis was applied.

Keywords

student movement; meanings; student organizations; young militants; revolutionary left.

\section{Explicación orgánica-contextual del movimiento estudiantil de Chile 2011}

El presente artículo, da a conocer algunos resultados obtenidos de la investigación "Ideas Políticas y Clivajes en el Movimiento Estudiantil Chileno", centrándose en el objetivo de identificar cómo jóvenes estudiantes y militantes de izquierda -que se autodefine marxista y revolucionaria- conceptualizan al movimiento estudiantil chileno posterior al 2011. Para ello, se utilizó un enfoque de carácter cualitativo, aplicándose un análisis de contenido a doce entrevistas en profundidad semi-estructuradas, realizadas a jóvenes militantes de distintas organizaciones políticas-estudiantiles de izquierda revolucionaria, las cuales se categorizaron en frentes intermedios, plataformas político estudiantiles y organizaciones políticas.

La problemática anteriormente planteada, se enmarca en un contexto de clímax del movimiento estudiantil y del despertar de la sociedad, pues desde inicios del siglo XXI, nos hemos ido encontrando con distintas movilizaciones estudiantiles que han sido de gran relevancia, entendiendo que durante toda la última década de los 90', Chile vivía en un letargo episodio de despolitización no sólo de la juventud sino que de toda la sociedad en general, como consecuencia de haber vivido diecisiete años de dictadura y el haber tenido una salida pactada a la democracia, esto se manifestó en lo que Norbert Lechner denominó como crisis de la cultura política ${ }^{4}$. Es por ello que, las distintas expresiones del movimiento estudiantil chileno desde el inicio del siglo $\mathrm{XXI}^{5}$, nos van demostrando la existencia de un proceso de politización ascendente -tal y como lo planteó el informe de Desarrollo Humano en el 20156- en donde cada experiencia ha contribuido para la organización política y la generación de conciencia frente a la construcción de relaciones sociales de manera integral.

\footnotetext{
${ }^{4}$ Norbert Lechner. Las sombras del mañana. La dimensión subjetiva de la política. Santiago, Ed. LOM, 2002.

5 2001: “El Mochilazo"; 2006: "Revolución Pinguina”; 2011: “La Primavera de Chile” o "El despertar de la sociedad".

${ }^{6}$ Rodrigo Márquez (Coordinador). Informe de desarrollo humano. Los tiempos de la politización. Santiago, PNUD, 2015.
} 
Es así que, el movimiento estudiantil que estalla el año 2011, marca un cambio de escenario político importante, no sólo porque su impacto "opera como expresión visible del malestar acumulado por la sociedad bajo el imperio de las políticas neoliberales"7, sino que también porque se incorpora un nuevo sujeto político, como por ejemplo el estudiante de universidad privada ${ }^{8}$.

Por su parte, cabe destacar que el movimiento estudiantil chileno del 2011 no nace espontáneamente, sino que -como se ha mencionado anteriormente- refleja la acumulación de experiencias provenientes principalmente del mundo secundario, ya que "los estudiantes universitarios venían cumpliendo hace al menos una década y media un ciclo de movilizaciones, la mayoría poco masivas, que se repetía año tras año, las que giraban en torno a demandas de reformas al sistema de educación superior dependiente de la agenda del gobierno y ministro de turno"9. No obstante, es el 2011, en que los estudiantes universitarios logran influir en la agenda gubernamental, demandando educación pública, gratuita y de calidad. Las primeras manifestaciones estudiantiles del año, se llevaron a cabo por los estudiantes de la Universidad Central, quienes estaban en contra de la venta del 50\% del plantel a la Sociedad de Inversores Norte Sur, de ahí que se comienza a masificar el discurso del fin al lucro en la educación como otra demanda. A esto se le suma "el retraso en la entrega de las becas y del pase escolar, así como la expectación generada por las propuestas del gobierno para la educación superior generaron el ambiente que derivó en una escalada de manifestaciones y protestas en las que se vieron involucrados los estudiantes de universidades públicas y privadas"10.

De esta manera, las movilizaciones estudiantiles del 2011 comenzaron a marcar las prioridades de la agenda del -ese entonces- Gobierno de Sebastián Piñera, cuestión que marca un giro en la dinámica de actuar del movimiento estudiantil.

Desde el punto de vista organizacional, el 2011 marcó visiblemente la disputa, entre las distintas organizaciones, del direccionamiento del movimiento estudiantil, en una primera instancia con las juventudes de partidos tradicionales, como las Juventudes Comunistas (JJ.CC), pero luego del 2011 con el llamado Bloque de Conducción ${ }^{11}$, manifestándose en las disputas por la vocerías de la Confederación de Estudiantes de Chile (ConfeCh). Es así que, según Marcelo Mella12 la plenaria del

\footnotetext{
7 Mario Garcés. El despertar de la sociedad. Los movimientos sociales en América Latina y Chile. Santiago, Ed. LOM, 2012, p. 137.

${ }^{8}$ Francisco Figueroa. Llegamos para quedarnos. Crónicas de la revuelta estudiantil. Santiago, Ed. LOM, 2013.

${ }^{9}$ Centro Alerta y OPECH. 2011: Aportes para interpretar una década de lucha por autoeducación. Santiago, Ed. Quimantú, 2012, p. 17.

10 Octavio Avendaño. “Fracturas y representación política en el movimiento estudiantil. Chile 2011". En Revista Última Década, N 41, Valparaíso, 2014, p. 49.

11 Coalición entre la Unión Nacional Estudiantil (UNE), Izquierda Autónoma (IA) y Frente de Estudiantes Libertarios (FEL)

12 Marcelo Mella. "Composición, correlaciones de fuerza y elaboración de estrategias en el pleno CONFECH (2011-2015). Chile. En Revista Última Década, № 45, Valparaíso, 2016, pp. 75-92.
} 


\section{Breve discusión conceptual del movimiento estudiantil chileno posterior al 2011: una visión desde las y los estudiantes revolucionarios}

ConfeCh durante los años 2011 y 2015 se conforman por cuatro fuerzas políticas de acuerdo al equilibrio entre identidad y estrategia:

a- Derecha: reúne a organizaciones como Gremialistas, Acción Liberal (AL) y la Juventud Demócrata Cristiana (JDC);

b- Centro: participan de este sector organizaciones de una izquierda más tradicional como por ejemplo las Juventudes Comunistas (JJ.CC), Juventudes Socialistas (J.S), Juventud Partido por la Democracia (JPPD) y Nueva Acción Universitaria (NAU) ${ }^{13}$;

c- Izquierda: dentro de este sector, participa el llamado Bloque de Conducción: Unión Nacional Estudiantil (UNE), Frente de Estudiantes Libertarios (FEL) e Izquierda Autónoma (IA);

d- Ultra-Izquierda ${ }^{14}$ : las organizaciones que conforman esta caracterización por su nivel de actoría son el Movimiento Popular Guachuneit (MPG), Grupos de Acción Popular (GAP), Movimiento De Izquierda Revolucionaria (MIR), Frente Estudiantil Revolucionario (FER), Juventud Guevarista (JG), Partido de Trabajadores Revolucionarios (PT), Fuerza Universitaria Rebelde (FUR), Juventud Rebelde (JR) y la Corriente Crítica Universitaria (CCU).

Es importante destacar que para efecto de este artículo, se trabaja con los discursos del sector que Marcelo Mella denomina como ultra-izquierda, pero que acá, y según los relatos de las y los entrevistados, se caracteriza como izquierda revolucionaria. También es importante esclarecer que existen más organizaciones que pertenecen a este sector y que no aparecen en la categorización del autor, pero que como se dijo anteriormente, las organizaciones estarán categorizadas en frentes intermedios, organizaciones políticas y plataformas político-estudiantiles.

\section{Breve historia del movimiento estudiantil chileno desde el siglo XX y XXI}

El movimiento estudiantil se puede entender como un actor importante del siglo XX, que permite reflexionar sobre la participación política de la juventud en los procesos de historización y transformación de la sociedad. Refleja además la influencia de los conflictos políticos tradicionales en la institución educativa universitaria, por ejemplo, Manuel Garretón nos cuenta que "la educación universitaria se había dividido con la creación de la Universidad Católica en 1888,

\footnotetext{
13 Esta última organización cumplió un rol fundamental en el direccionamiento de la lucha por la reforma educacional, tanto así que los ex dirigentes de esta organización, forman el Partido Revolución Democrática, que se legaliza el 2016, consiguiendo representación en la Cámara de Diputados tanto para las elecciones presidenciales del 2014 como también para las últimas elecciones del 2018, que además de aumentar su representación de Diputados, logran un escaño en la Cámara del Senado.

14 La categoría de ultra izquierda podría disputarse, ya que generalmente se utiliza para 1) la criminalización e infatilización a sectores que se autodefinen como revolucionarios, o 2) que sencillamente se encuentran fuera de la lógica del sistema político tradicional, ya que incluso el llamado Bloque de Conducción también fue denominado como ultraizquierda por los medios de comunicación, para el autor Marcelo Mella el Bloque de Conducción se encontraría dentro de la categoría de Izquierda.
} 
donde se atrincheró toda la elite católica. La Universidad de Chile en cambio tenía una tradición laica firmemente establecida"15.

La 'cuestión social', el sistema parlamentarista, marcaron un contexto que determinó la necesidad del surgimiento de organizaciones estudiantiles, que transversalmente está ligado con la cuestión de clase, ya que "las primeras organizaciones estudiantiles datan de comienzos de siglo, cuando a la Universidad de Chile comienzan a ingresar jóvenes provenientes de los grupos medios, muchos de ellos de provincia. Las nuevas organizaciones, acordes con el clima que ya se respiraba en la sociedad, poseían tres tendencias fundamentales: gran preocupación por la "cuestión social"; un anticlericalismo militante y mentalidad laica; una gran fe en el progreso y en la ilustración como instrumento del cambio social"16.

En ese sentido, el surgimiento de la Federación de Estudiantes de la Universidad de Chile en 1906, marca un proceso en que, a palabras de Gabriel Salazar, la Universidad se convierte en un "crisol de fusiones históricas de largo alcance"17, es decir una fusión dialéctica entre la juventud peonal ${ }^{18}$, con la juventud oligarca y media. No obstante, "el origen del movimiento estudiantil chileno, convencionalmente, se ubica en la década de 1920 y 1930"19, y el cual en un principio posee una influencia anarquista y libertaria, es por ello que se puede establecer que su surgimiento en el siglo XX "nace en un período marcado por el ascenso de formas modernas de la política, en las que la participación de las masas se hizo fundamental, y en que las posiciones políticas asumidas por los sectores populares tendieron a la reforma profunda del orden oligárquico tradicional" ${ }^{20}$. Sin embargo, a medida que avanza el siglo XX, la conformación social del movimiento estudiantil va mutando de acuerdo al contexto nacional e internacional, ya que "si bien el movimiento estudiantil siempre estuvo junto a los sectores populares en sus luchas, la mayor parte del tiempo no fue un movimiento fuertemente ligado a la izquierda. De partida, porque el carácter social de los estudiantes era más bien elitaria y con el correr del siglo XX se le integraron los sectores de las capas medias, principalmente hijos de funcionarios, profesionales liberales y profesores normalistas"21, lo que no impidió que dentro de las universidades se pudieran constituir organizaciones de militantes

\footnotetext{
15 Manuel Garretón. El movimiento estudiantil: conceptos e historia. T. IV, Santiago, Ed. Sur, 1984, p. 64.

16 Ibídem.

17 Gabriel Salazar. Historia de Chile. Niñez y juventud. T. V, Santiago, 2014, p. 111.

${ }^{18}$ El peonaje como tal se puede concebir como parte de la estructura social del sistema de Hacienda que se implementó durante el desarrollo de la colonización hasta -incluso- principios del siglo XX y que representaba la mano de obra barata. Por su parte, la juventud como categoría es más compleja de analizar en este período de tiempo, no obstante para el contexto que habla G. Salazar, juventud peonal se puede entender -en el marco del inicio de la cuestión social- como aquella juventud proveniente de sectores empobrecidos y populares, ya sean del campo o la ciudad.

${ }^{19}$ Marcelo Mella, Héctor Ríos y Ricardo Rivera. "Condiciones orgánicas y correlaciones de fuerza del movimiento estudiantil chileno. Una aproximación desde la Confech (2011-2015)". En Revista Izquierdas, $\mathrm{N}^{\circ}$ 27. Santiago, 2016, p. 131.

20 Luis Thielemann. La anomalía social de la transición. Movimiento estudiantil e izquierda universitaria en el Chile de los noventa (1987-2000). Santiago, Ed. Tiempo Robados, 2016, p.33

${ }^{21}$ Ibídem, p.34
} 


\section{Breve discusión conceptual del movimiento estudiantil chileno posterior al 2011: una visión desde las y los estudiantes revolucionarios}

de izquierda con distintas caracterizaciones. En primer lugar, en la década de los 60' no se puede desconocer la influencia de la Revolución Cubana, ya que se considera como un "hito que cambió las estrategias y tácticas de las organizaciones de izquierda revolucionarias, las que apuntarían a la emergencia de guerrillas en oposición a la creación de frentes populares interclasistas, que promovía la Unión Soviética"22, es en este contexto que los movimientos estudiantiles y juveniles también se mueven.

En términos generales -en el mismo período-, éstos se caracterizaron por asumir un compromiso de doble militancia, una orientada al partido y otra a los frentes de masas; durante la dictadura esta lógica militante se desfiguró debido a la fuerte represión, y obligó a que el vínculo político-social fuese reconfigurado hacia un activismo cultural, ya que las instancias de representación estudiantil no fueron reconocidas por el Estado; por último, durante la transición democrática, a pesar que los partidos se insertaron nuevamente en el sistema político 23 "la mantención de la Constitución autoritaria y el modelo económico, generó la desarticulación de las militancias partidistas de masas en la izquierda universitaria ${ }^{24}$.

En este sentido, sería importante entonces conocer los distintos períodos del movimiento estudiantil chileno con el fin de comprender el contexto de cada uno de ellos, para esto Víctor Muñoz y Carlos Durán proponen la siguiente periodización ${ }^{25}$

\begin{tabular}{|c|c|c|c|}
\hline Período & Denominación & Características contextuales & $\begin{array}{l}\text { Termina } \\
\text { cuando }\end{array}$ \\
\hline $\begin{array}{l}1967- \\
1973\end{array}$ & $\begin{array}{l}\text { "Lucha en torno a } \\
\text { los escenarios, las } \\
\text { posibilidades y los } \\
\text { límites de la } \\
\text { política" }\end{array}$ & $\begin{array}{l}\text { Influencia de los discursos } \\
\text { revolucionarios / Politización de } \\
\text { movimientos reformistas } \\
\text { universitarios }\end{array}$ & Golpe de Estado \\
\hline $\begin{array}{l}1973- \\
1982\end{array}$ & $\begin{array}{c}\text { “Apelación } \\
\text { patriótica, apolítica } \\
\text { y de unidad } \\
\text { nacional, versus } \\
\text { resistencia cultural" }\end{array}$ & $\begin{array}{c}\text { Establecimiento de una nueva } \\
\text { Constitución: Estado subsidiario y } \\
\text { Consolidación del neoliberalismo } \\
\text { / Ley General de Universidades } \\
\text { /Importancia de la militancia } \\
\text { oficialista y su influencia } \\
\text { discursiva de unidad nacional y } \\
\text { patriotismo apolítico / Militancia } \\
\text { de izquierda universitaria }\end{array}$ & $\begin{array}{l}\text { Crisis política y } \\
\text { económica }\end{array}$ \\
\hline
\end{tabular}

22 Camila Araya. "Resurgimiento de las organizaciones estudiantiles de izquierda revolucionaria. Percepciones y autodefinición de los actores”. En Revista de Estudios Políticos y Estratégicos, Vol. 5, $\mathrm{N}^{\circ} 2,2017$, p. 83.

23 Víctor Muñoz. Generaciones. Juventud universitaria e izquierdas políticas en Chile y México (Universidad de Chile - UNAM 1984-2006). Santiago. Ed. LOM, 2011.

24 Ibídem, p. 189.

25 Víctor Muñoz y Carlos Durán. “Los jóvenes y los movimientos estudiantiles en el Chile reciente. Ciclos sociopolíticos entre 1967 y 2017”. En Revista Izquierdas, № 45. Santiago, 2019 [adelanto de edición], pp. 129-159 


\begin{tabular}{|c|c|c|c|}
\hline & & $\begin{array}{c}\text { orientada a la resistencia, desde el } \\
\text { activismo cultural }\end{array}$ & \\
\hline $\begin{array}{l}1983- \\
1989\end{array}$ & $\begin{array}{l}\text { "Democracia versus } \\
\text { dictadura. La } \\
\text { formalización } \\
\text { política oficialista y } \\
\text { los caminos de la } \\
\text { sublevación, la } \\
\text { protesta y la } \\
\text { transición en la } \\
\text { oposición" }\end{array}$ & $\begin{array}{c}\text { Politización pública del } \\
\text { movimiento estudiantil en la } \\
\text { dicotomía democracia-dictadura/ } \\
\text { Emergencia protesta social por la } \\
\text { crisis de la deuda/ Apertura del } \\
\text { diálogo con los sectores } \\
\text { opositores }\end{array}$ & $\begin{array}{l}\text { "inicio" de la } \\
\text { transición } \\
\text { democrática }\end{array}$ \\
\hline $\begin{array}{l}1990- \\
2005\end{array}$ & $\begin{array}{c}\text { "Crisis de la } \\
\text { politicidad social } \\
\text { juvenil y politización } \\
\text { a contracorriente" }\end{array}$ & $\begin{array}{l}\text { La democracia mantuvo el modelo } \\
\text { económico neoliberal / Enclaves } \\
\text { autoritarios / Vaciamiento social } \\
\text { del sistema político Influencia } \\
\text { discursiva sobre la técnica y } \\
\text { eficiencia / Pérdida de } \\
\text { valoraciones ideológicas / } \\
\text { Desarticulación temporal del } \\
\text { movimiento estudiantil / } \\
\text { Desencanto y politización } \\
\text { defensiva/ Surgimiento de } \\
\text { colectivos políticos al interior de } \\
\text { las universidades }\end{array}$ & $\begin{array}{l}\text { Cuestionamiento } \\
\text { a los ejes } \\
\text { estructurales del } \\
\text { modelo }\end{array}$ \\
\hline $\begin{array}{l}2006- \\
2011\end{array}$ & $\begin{array}{c}\text { "Politización } \\
\text { ascendente, } \\
\text { interpelación a la } \\
\text { sociedad } \\
\text { y disputa por la } \\
\text { política". }\end{array}$ & $\begin{array}{c}\text { Influencia de un discurso de } \\
\text { participación ciudadana que } \\
\text { generó fuertes expectativas / } \\
\text { Revolución Pinguina: rearme de la } \\
\text { organización estudiantil / } \\
\text { Cuestionamiento de la estructura } \\
\text { desde el mundo estudiantil / } \\
\text { Influencia del mundo estudiantil } \\
\text { en la agenda política }\end{array}$ & $\begin{array}{l}\text { Rompimiento } \\
\text { del sentido } \\
\text { común de la } \\
\text { política } \\
\text { tecnocrática y la } \\
\text { despolitización } \\
\text { social }\end{array}$ \\
\hline $\begin{array}{l}2011- \\
2017\end{array}$ & $\begin{array}{c}\text { “De la política de los } \\
\text { campus a la política } \\
\text { nacional. } \\
\text { Repartidización y } \\
\text { reconfiguración del } \\
\text { campo político" }\end{array}$ & $\begin{array}{c}\text { Irrupción de las movilizaciones } \\
\text { sociales más grandes desde el } \\
\text { retorno a la democracia / } \\
\text { Capitalización de las demandas } \\
\text { estudiantiles y surgimiento del } \\
\text { Frente Amplio (FA) / Surgimiento } \\
\text { de nuevas organizaciones y } \\
\text { repartidización de las } \\
\text { organizaciones estudiantil- } \\
\text { juveniles / Influencia del } \\
\text { movimiento estudiantil en la } \\
\text { agenda política que permitió que } \\
\text { se desarrolle una reforma } \\
\text { educacional / }\end{array}$ & -- \\
\hline
\end{tabular}

\section{Fuente: elaboración propia en base a Víctor Muñoz y Carlos Durán}

La propuesta de periodización, nos refleja muy brevemente las mutaciones que ha ido teniendo el movimiento estudiantil desde la mitad del siglo XX hasta la actualidad, en donde aún no se podría definir cuál sería el cierre del ciclo, ya que sigue en trámite la reforma educacional, la cual -estratégicamente- se fue legislando 


\section{Breve discusión conceptual del movimiento estudiantil chileno posterior al 2011: una visión desde las y los estudiantes revolucionarios}

divididamente por proyecto, lo que ha significado una desarticulación para el movimiento estudiantil y el retorno del manejo de la agenda pública tanto por parte del Gobierno de Michelle Bachelet (2014-2018) como la de Sebastián Piñera (20182022), en un contexto donde los principales líderes estudiantiles del 2011 llegaron al Parlamento.

\section{Cómo se concibe el movimiento estudiantil chileno}

Actualmente no se puede entender al movimiento estudiantil chileno bajo una definición constante en el tiempo, porque sus dinámicas van cambiando de acuerdo al direccionamiento estratégico que este tenga, por lo que pueden surgir diversas definiciones. De esta manera la Facultad Latinoamericana de Ciencias Sociales (FLACSO) lo define -durante el período 2011-2016- "como un movimiento social que cuenta con una lógica orgánica propia y unas demandas e ideologías políticas coherentemente definidas" 26 . Sin embargo, en esta oportunidad y enfocado en el mismo período, me gustaría definirlo, como un campo de disputa política, debido a tres razones.

La primera se relaciona con lo que decía Salazar ${ }^{27}$, sigue existiendo una fusión dialéctica entre la juventud de sectores populares (ya no peonal) y la juventud de sectores medios y adinerados (ya no oligarcas), sin embargo el reconocerse de un sector u otro asume la postura desde donde se debe organizar políticamente. La segunda, porque a nivel orgánico ConfeCh, puede que las demandas e ideología de quien la conduzca estén coherentemente definidas. Pero, dentro de los actores que conforman el movimiento estudiantil -en este caso- militantes de distintas organizaciones, las definiciones aún están en construcción. Y por último, porque las definiciones y formas de cómo se debería llevar a cabo la movilización estudiantil que están en construcción-, son las que entran en disputa. Por lo tanto, se puede concebir al movimiento estudiantil chileno como la expresión de un proceso histórico -que tendrá distintas dinámicas y significaciones, dependiendo del contexto-, en donde las y los sujetos que lo movilizan se encuentran construyendo un proyecto, que contempla la proyección de la transformación social, desde una determinada política.

Por otro lado, y retomando a Salazar ${ }^{28}$, hay que tener en cuenta que el contexto ha cambiado, pues la fusión dialéctica de clases es distinta, ya que hoy, tal cual como lo fue la política estalinista con los frentes populares, existe una facilidad de ejecutar consensos entre distintos sectores, sobre todo a nivel Confech, que ha logrado generar demandas conjuntas entre todas sus corrientes, exceptuando al movimiento gremial. Pero, lo que más llama la atención es cómo se va significando

\footnotetext{
26 Lucía Miranda (coordinadora). Protestar es de buena educación. Orgánica, demandas e ideología del Movimiento Estudiantil Chileno. Santiago, FLACSO, 2016, p. 13.

27 Gabriel Salazar. Historia de Chile. Niñez y juventud. T. V, Santiago, 2014.

28 Ibíd.
} 


\section{Camila Ignacia Araya Guzmán}

el movimiento estudiantil desde el mundo universitario, en base a un análisis estructural, ya que, con los procesos de mercantilización y privatización de la educación -por parte de la dictadura de Pinochet-, que dio origen al negocio de las universidades privadas, ha generado la privatización del espacio estudiantil -como una trinchera de lucha- y del conocimiento, por lo que este ya no es considerado como un elemento importante para la transformación social.

De este modo, las universidades públicas se han convertido en reproductoras de la elite, ya que -como se dijo en un momento- este espacio se despeonizó. Mientras que en las universidades privadas, gracias al derecho de endeudamiento a través de los créditos, se ha ido -por decirlo de algún modo- proletarizando, y es así como lo perciben las y los entrevistados

“...el movimiento estudiantil es una cuestión...sobre todo las universidades estatales, bastante cuicos, por decirlo así, bastante clase alta, es la universidad privada donde mayoritariamente existe el estudiantado de sectores de menores recursos, más popular, pero es un estudiantado que muchas veces pasa, que lo único que quiere es entrar a la universidad, terminar y ponerse a trabajar, no porque quiera ganar plata y ser millonario sino porque está buscando sacar a su familia adelante..." 29

También se percibe que el capital temporal permite un trabajo militante, el cual permite la elitización de la condición de izquierda, puesto que aquellos que trabajan -por necesidad- y estudian, no poseen el tiempo para desarrollar la militancia, de ahí la dificultad para avanzar en las transformaciones sociales que pueda plantear una izquierda universitaria

“...pasa también que la izquierda en el mundo estudiantil, llega a ser... no todos obviamente, pero tiene su sector medio elite también metido. Entonces en ese sentido es difícil luchar contra eso, de que las personas logren decir están todos los sectores... mira vamos a avanzar y hay que luchar por las transformaciones políticas, sociales, económicas, culturales del país y eso implica tener una conciencia de clase..."30

Por otro lado, tenemos que históricamente, y visto desde una perspectiva marxista y de clase, el sujeto estudiante se ha considerado como una fuerza auxiliar que acompaña al trabajador en su lucha, lo cual se refleja en consignas tales como "hoy estudiantes, mañana trabajadores" o "de la sala de clases a la lucha de clases". Otros ven en el movimiento estudiantil el único espacio en donde se ha permitido que la izquierda revolucionaria tenga relevancia en el siglo XXI

\footnotetext{
${ }^{29}$ Entrevista realizada a Claudio, militante Frente Intermedio 2, mayor de edad, Universidad Privada de Santiago.

30 Ibídem.
} 


\section{Breve discusión conceptual del movimiento estudiantil chileno posterior al 2011: una visión desde las y los estudiantes revolucionarios}

“...el movimiento estudiantil es la única franja social que en la cual esta izquierda, o la izquierda revolucionaria ha tenido cierto asidero, ha conducido u orientado ciertos procesos de movilización a través de sus instrumentos más representativos que son las federaciones y la CONFECH, y ahí hay hartas disputas..."31

Sin embargo, y desde una visión negativa, el movimiento estudiantil a partir del 2011, no sólo significaría el espacio que le permitiría a la izquierda revolucionaria (re)construirse, sino que también -en tanto espacio público- se prestó para la capitalización identitaria de las distintas orgánicas, lo cual moral y éticamente es mal visto dentro de la militancia universitaria

“...después del 2011 el movimiento estudiantil quedo ahí como una especie de escenario publico donde llegaba cualquier dirigente, planteaba sus cosas y..."sah mira yo estoy con estos cabros y podría salir en la prensa y darse a conocer"..." 32

En este sentido, es que el 2011 como fecha, asume una importante relevancia, puesto que se reconoce como el inicio de un nuevo ciclo político, que por supuesto está caracterizado por las movilizaciones estudiantiles del momento, pero también por la acumulación de protestas desde inicios de los 90’

“...el resquebrajamiento del sentido común neoliberal, y la irrupción de las masas como actor político, no es algo que le atribuyamos únicamente al movimiento estudiantil..."33

Si bien no se le puede atribuir toda la responsabilidad al movimiento estudiantil del 2011 de este nuevo ciclo político, si se considera como la única franja social que realiza una crítica estructural del modelo neoliberal chileno, al diferenciar los tipos de demandas de otras manifestaciones. Esta diferenciación asume importancia, ya que permite, no sólo analizar la perspectiva política que puedan tener los sectores que impulsan las demandas, sino que también refleja el proceso de politización de la sociedad y sus distintos sectores, generando la apertura para el surgimiento de nuevas organizaciones o reestructuración de las ya existentes

“...desde los 2000 en adelante la única franja social en Chile que entraba a cuestionar pilares estructurales del modelo neoliberal era el movimiento estudiantil po', más allá desde lo que por ejemplo el 2006 los del cobre quemaron diez camiones en el norte, pero eran demandas reivindicativas, economicistas que iban en función de satisfacer sus intereses inmediatos, que en este caso eran las condiciones de trabajo

\footnotetext{
31 Entrevista realizada a Ramón, militante Organización Política-Estudiantil 4, mayor de edad, Universidad Pública de Concepción.

32 Entrevista realizada a Claudio, militante Frente Intermedio 2, mayor de edad, Universidad Privada de Santiago.

33 Entrevista realizada a Pablo, militante Organización Política-Estudiantil 3, mayor de edad, Universidad Privada de Santiago
} 
laboral y materiales de vida que poseían los trabajadores del cobre. Pero, el movimiento estudiantil fue a cuestionar más allá de cuestiones económicas, dio el salto cualitativo de comenzar con este cuestionamiento más político, y fue la primera demanda que desde la salida de la dictadura, desde la salida pactada en adelante, que entra en contradicción con el modelo neoliberal, es decir, recuperar algo que había tomado el mercado ehhh y recuperarlo como derecho social como históricamente había sido anteriormente (...) Entonces, ocurre eso el 2011 y ahí vimos la necesidad po, que no podíamos seguir con estas políticas o este tipo de trabajo político más compartimentado, más ehhh underground, más semi clandestino por así decirlo, sino que teníamos que abrirnos a desarrollar política social"34

Desde esta lógica se evidencia la idea de necesidad en función de explicar las razones de surgimiento, resurgimiento o visibilización de las organizaciones de izquierda revolucionaria, que se pueden caracterizar en 1) la necesidad de reestructurarse de acuerdo a los conflictos del contexto nacional; 2) la necesidad de hacerle frente a la izquierda tradicional del espacio universitario; 3) la necesidad de brindar organicidad a las experiencias de los distintos encuentros al calor de las movilizaciones estudiantiles del siglo XXI, que también se traducen en la trayectoria del paso de la vida estudiantil escolar a la vida estudiantil universitaria; y 4) desde una visón táctica organizacional, se establece la necesidad de creación de frentes intermedios para generar el vínculo con sectores que no se estaba llegando 35 .

El 2011, asume una significación importante a la hora de comprender el movimiento estudiantil chileno como una apertura a un nuevo ciclo político que se venía desarrollando con anterioridad. Pero, por otro lado, esta fecha en cuanto a efectos de movilización, expectativas a largo plazo, apoyo ciudadano y de distintos sectores se va diluyendo -según las y los entrevistados-, afirmando que precisamente

“...el 2011 lo que tenía era que efectivamente permeaba y llegaba a la mayoría de la población..." 36

No obstante, la diferencia de lecturas, hace que el movimiento estudiantil carezca de claridad política, precisamente porque quienes lo conducen generan prácticas de carácter mediático más que político, en donde los análisis referentes al movimiento estudiantil se centran en los liderazgos principales, más que en las bases estudiantiles que es donde se generan las discusiones, los conflictos y las disputas. Un ejemplo de esto fue la llamada Ofensiva Estudiantili ${ }^{37}$, y el análisis que se presenta sobre esto fue que

\footnotetext{
34 Entrevista realizada a Ramón, militante Organización Política-Estudiantil 4, mayor de edad, Universidad Pública de Concepción

35 Camila Araya. "Resurgimiento de las organizaciones estudiantiles de izquierda revolucionaria. Percepciones y autodefinición de los actores". En Revista de Estudios Políticos y Estratégicos, Vol. 5, $\mathrm{N}^{\circ} 2$, 2017, pp. 80-102

36 Entrevista realizada a Pablo, militante Organización Política-Estudiantil 3, mayor de edad, Universidad Privada de Santiago.

${ }^{37}$ La Ofensiva Estudiantil fue la consigna con que un grupo estudiantes y militantes de la Asamblea de Estudiantes Secundarios (ACES) junto con la Juventud Rebelde (JR) -hoy Unión Rebelde (UR)-,
} 


\section{Breve discusión conceptual del movimiento estudiantil chileno posterior al 2011: una visión desde las y los estudiantes revolucionarios}

“...si uno hace un análisis del 2011 hasta hoy día, el movimiento estudiantil ha madurado en experiencia, pero en términos de claridades políticas no cachay, y en ese sentido creemos que la ofensiva careció completamente de una claridad política de cómo hoy día enfrentar la lucha por la educación gratuita, y que más bien se transformó en una lucha coyuntural, mediática, pero que los distintos centros de universidades, o en los mismos colegios la discusión nunca, o por lo menos en los espacios que nosotros hemos estado como directamente frente a la reforma, nunca se dio esa discusión, sino más bien fueron reivindicaciones internas que se trataron de unir con una demandad que vine desde el 2011"38

En consecuencia, el movimiento estudiantil chileno actual, en el contexto de la reforma educacional, se significa desde la atomización orgánica y dirigencial que lo moviliza, cuyo riesgo se refleja en el sentimiento de la derrota

“...entonces el movimiento estudiantil ya se desgastó, nosotros vemos que ya nos derrotaron, la lucha por la educación ya sufrió la derrota, sufrimos una derrota y va a ser difícil nosotros volver a retomar procesos más de avanzada en función de lo que plantea el Gobierno, sí va a estar a la palestra el tema de la educación, pero va a ser difícil ya poner o tratar de imponer la voluntad en el Gobierno a través de una movilización a largo plazo, masiva y legítima como lo fue el 2011"39

Este sentimiento de derrota, que asume un riesgo, se puede traducir en una determinada institucionalización del proceso de politización que se ha venido creando, lo cual de manera dialéctica, dificultaría la avanzada construcción de la izquierda revolucionaria.

\section{Reflexiones finales}

Para finalizar, debemos tener presente que el movimiento estudiantil chileno en el período 2011-2016, se definió como un proceso histórico, que tiene distintas dinámicas y significaciones, porque depende del contexto en que se manifieste, es en este contexto donde las y los sujetos que dan forma a este proceso, intentan construir un proyecto de transformación social, de acuerdo a una política táctica y estratégica determinada.

En este sentido, a través de los relatos de las y los entrevistados, podemos identificar dos perspectivas de análisis dicotómicas que brindan significancia

\footnotetext{
hicieron ocupación del Palacio Presidencial La Moneda, haciéndose pasar por turistas dejando el mensaje "Notifíquese: hoy comienza la ofensiva", el 24 de mayo del 2016.

38 Entrevista realizada a Violeta, militante Frente Intermedio 4, mayor de edad, Universidad Privada de Santiago.

39 Entrevista realizada a Ramón, militante Organización Política-Estudiantil 4, mayor de edad, Universidad Pública de Concepción.
} 


\section{Camila Ignacia Araya Guzmán}

conceptual al movimiento estudiantil. Por un lado, tenemos una perspectiva de análisis positiva, que se manifiesta en la apertura de un nuevo ciclo político, que se venía gestando con las distintas experiencias de movilizaciones estudiantiles iniciadas a principios del año 2000, y que apuntan a establecer demandas de carácter estructural criticando la sociedad neoliberal.

Además de lo anterior, el movimiento estudiantil chileno, como espacio público de participación política, es considerado importante para el funcionamiento de una izquierda tradicional, pero también para la (re)construcción o visibilización de una izquierda revolucionaria en el siglo XXI, tenga esta incidencia o no en el plano legislativo, ya que la incidencia que se refleja es en la apertura que brinda el contexto para la activación de organizaciones que se posicionan desde la autodefinición de la categoría revolucionaria.

Por otro lado, tenemos una perspectiva de análisis negativa sobre el movimiento estudiantil, puesto que se considera que este espacio, como consecuencia de la privatización del sistema educativo derivó en la consolidación de su elitización, significando que incluso la disputa del conocimiento ya no fuera una trinchera de lucha.

Esta elitización del espacio universitario, no sólo se refleja en la pérdida de la concepción de trinchera de lucha, sino que también se vincula con la militancia política estudiantil, puesto que se considera la existencia de una elitización del trabajo militante, sobre todo de izquierda, que está determinada por un capital temporal de las y los estudiantes según las necesidades que ellos tengan. Lo anterior se traduce en el claro ejemplo de que existen estudiantes que deben estudiar y trabajar y otros que no, en un contexto en donde no existe un determinado desarrollo de la conciencia de clase producto de la neoliberalización de la vida privada cotidiana y la desarticulación de la vida social, lo cual reduce la capacidad de acciones militantes.

El otro problema que gira en torno a la militancia, es que el movimiento estudiantil -y reitero, en tanto espacio público- se capitaliza de manera identitaria para las propias organizaciones que lo componen, y entra en dilema con la ética y moral militante. Esta crítica que se plantea, se debe a que el movimiento estudiantil se encuentra totalmente atomizado, significando la pérdida de claridad política al interior de este. Evidentemente, el 2011 el movimiento estudiantil mostró públicamente una unificación y coherencia en sus planteamientos a pesar de la existencia de diversas organizaciones y conflictos internos, sin embargo, desde el 2014 cuando entra a discutirse la reforma educacional, las diferencias se comienzan a hacer más visibles, por lo que la atomización de este les jugó en contra, ya que con la llegada del segundo gobierno de Michelle Bachelet, las demandas se capitalizaron e institucionalizaron, al igual que algunas organizaciones estudiantiles, significando poco asidero del movimiento estudiantil en lo que respecta a la reforma educacional. 


\section{Bibliografía}

Camila Araya. "Resurgimiento de las organizaciones estudiantiles de izquierda revolucionaria. Percepciones y autodefinición de los actores". En Revista de Estudios Políticos y Estratégicos, Vol. 5, ํ2, 2017, pp. 80-102

Centro Alerta y OPECH. 2011: Aportes para interpretar una década de lucha por autoeducación. Santiago, Ed. Quimantú, 2012

Gabriel Salazar. Historia de Chile. Niñez y juventud. T. V, Santiago, 2014.

Lucía Miranda (coordinadora). Protestar es de buena educación. Orgánica, demandas e ideología del Movimiento Estudiantil Chileno. Santiago, FLACSO, 2016.

Luis Thielemann. La anomalía social de la transición. Movimiento estudiantil e izquierda universitaria en el Chile de los noventa (1987-2000). Santiago, Ed. Tiempo Robados, 2016

Manuel Garretón. El movimiento estudiantil: conceptos e historia. T. IV, Santiago, Ed. Sur, 1984.

Marcelo Mella, Héctor Ríos y Ricardo Rivera. “Condiciones orgánicas y correlaciones de fuerza del movimiento estudiantil chileno. Una aproximación desde la Confech (2011-2015)". En Revista Izquierdas, $N^{\circ}$ 27. Santiago, 2016, pp. 124-160.

Marcelo Mella. "Composición, correlaciones de fuerza y elaboración de estrategias en el pleno CONFECH (2011-2015). En Revista Última Década, $N^{\circ}$ 45, Valparaíso, 2016, pp. 75-92.

Octavio Avendaño. "Fracturas y representación política en el movimiento estudiantil. Chile 2011”. En Revista Última Década, N 41, Valparaíso, 2014, pp. 41 68.

Víctor Muñoz y Carlos Durán. "Los jóvenes y los movimientos estudiantiles en el Chile reciente. Ciclos sociopolíticos entre 1967 y 2017". En Revista Izquierdas, N ${ }^{\circ}$ 45. Santiago, 2019 [adelanto de edición], pp. 129-159

Víctor Muñoz. Generaciones. Juventud universitaria e izquierdas políticas en Chile y México (Universidad de Chile - UNAM 1984-2006). Santiago. Ed. LOM, 2011.

Recibido: 30/06/2018

Evaluado: $15 / 07 / 2018$

Versión Final: 15/08/2018 